\title{
Improvement of the workplace environmental physical factors values monitoring by determining the optimal interval for their control
}

\author{
O. Kruzhilko a, ${ }^{\star}$, O. Polukarov b, V. Kalinchyk b, I. Tkalych a \\ a Public Agency "National Scientific and Research Institute of Industrial Safety \\ and Occupational Safety and Health", 04060, Vavilovykh str.,13, Kyiv, Ukraine \\ b National Technical University of Ukraine "Igor Sikorsky Kiev Polytechnic Institute", \\ 03056, Prosp. Peremohy, 37, Kyiv, Ukraine \\ * Corresponding e-mail address:
}

\section{ABSTRAGT}

Purpose: Determination of such an interval of workplace environmental physical factors control, which would ensure high monitoring reliability and the minimum data collection and processing duration (or cost).

Design/methodology/approach: To achieve the goal were applied: analysis and synthesis of known scientific results on the topic of research, statistical analysis, mathematical modelling. Statistical data for determining the interval of control was recorded at regular intervals.

Findings: A methodology has been developed for determining the interval of workplace environmental physical factors values control. It is based on the identification of patterns of change in the physical factors values. The algorithm of workplace environmental physical factors values control is proposed, which helps to identify cases when the actual values of the factors exceed the limit values. The practical application of theoretical propositions showed that the correlation coefficient between the factual sample and the sample formed using the determined control interval is within $0.74 \ldots . .0 .88$, which satisfies the condition $\mathrm{R}>0.5$ as intended.

Research limitations/implications: The mechanism for workplace environmental physical factors values monitoring was further developed on the basis of forecasting changes in the physical factors values and determining the duration of the excess of the factors values over the limit. In this study on stationary and conditional stationary processes was the focus.

Practical implications: The use of the algorithm that is based on the methodology for determining the interval of workplace environmental physical factors values control contributes to more effective monitoring of working safety.

Originality/value: For the first time justified by the choice of the control interval of workplace environmental physical factors values with acceptable accuracy of the forecast that allow to quickly establish working conditions hazard class. 
Keywords: Safety and health management, Workplace environmental physical factors, Algorithmization

\section{Reference to this paper should be given in the following way:}

O. Kruzhilko, O. Polukarov, V. Kalinchyk, I. Tkalych, Improvement of the workplace environmental physical factors values monitoring by determining the optimal interval for their control, Archives of Materials Science and Engineering 99/1-2 (2019) 42-49.

\section{MATERIALS MANUFAGTURING AND PROGESSING}

\section{Introduction}

Almost all industries are characterized by the workplace environmental physical factors presence, which negatively affect human health during employment [1-3]. Wherein the worst working conditions in the mining industry (coal) $[4,5]$ and in the manufacturing (chemical, metallurgical, mechanical engineering) are observed [6-9].

The research results convincingly indicate the combined effect of workplace environmental physical factors on human health, and these factors can be considered the most significant in terms of adverse effects on workers [10]. This study sets out the results of workplace environmental physical factors analysis of chemical enterprises, primarily glass and glass products.

The starting materials for the manufacture of glass are: quartz sand (silicon dioxide, $\mathrm{SiO}_{2}$ ), it's maximum permissible concentration (MPC) $-1 \mathrm{mg} / \mathrm{m}^{3}$ at a concentration of more than $60 \%$, aerosol mainly fibrogenic action); soda ash (sodium carbonate, $\mathrm{Na}_{2} \mathrm{CO}_{3}$ ), it's MPC $2 \mathrm{mg} / \mathrm{m}^{3}$ ); limestone or chalk (calcium carbonates of $\mathrm{CaCO}_{3}$ ), it's MPC $-2 \mathrm{mg} / \mathrm{m}^{3}$ ).

Auxiliary materials are: dyes that add a certain colour (oxides of lead, copper, boron); silencers, which are distributed in the glass in the form of small particles and scatter light and form a glass of milky white colour (phosphoric acid, fluoride salts); decolourants that eliminate the staining of glass from iron oxides (nickel oxide, selenium, manganese compounds); clarifiers that remove gas inclusions (bubbles) from the melt (arsenic trioxide, nitrate); accelerators that accelerate the process of glass cooking (compounds of fluorine, boron, chlorine).

Currently, the main method of assessing occupational risk is workplace certification for working conditions, with which the conformity of the work environment with its normative characteristics according to individual risk factors is established [11]. However, this approach does not allow evaluating the complex and operational combination of the effects of all risk factors on the human body. This is due to the fact that occupational hazards factors levels can change significantly even with constant technological processes. Therefore, it is necessary for the enterprise to ensure constant monitoring of workplace environmental physical factors values, as well as predict the development of these values changes.

Usually, the environmental physical factors influence level on employees can be established expertly, using, in particular, the known method of strict ranking $[12,13]$. Specialists who have the necessary knowledge and experience in solving such problems are involved in the expert survey. In this case, the experts should be familiar with the specificity of the equipment and technological processes functioning used in the glass and glassware manufacturing enterprise, to know the basic provisions of the current regulatory documents.

In the controlling process the working conditions condition, an important task is to determine the intervals of control of the environmental dangerous and harmful factors. This is due to the fact that on the one hand, lowering this interval leads to unreasonable costs of factors values monitoring, and on the other hand, unreasonable interval value increase can ensure the absence of factors values registration that exceed permissible [14].

Therefore, the purpose of this study is determination of such an interval of workplace environmental physical factors control, which would ensure high monitoring reliability and the minimum data collection and processing duration (or cost).

\section{Materials and methods}

To achieve the goal were applied: analysis and synthesis of known scientific results on the topic of research, statistical analysis, mathematical modelling.

Statistical data for determining the interval of control was recorded at regular intervals.

Based on the analysis of workplace environmental physical factors values, three process groups were identified:

- Non-stationary;

- Stationary;

- Conditional stationary.

For workplace environmental physical factors, whose dynamics level is a non-stationary process, the control 
interval can be determined by expert methods that are currently well understood $[12,13]$. In this study on stationary and conditional stationary processes was the focus.

Conditional stationary processes were divided into two groups:

1) Expectation and variance of process values does not significantly depend on time (variation of expectation within $15 \%$ );

2) Processes in the values of which a trend component can be distinguished, and the remainder will satisfy the condition for limiting the variation in the mathematical expectation of the remainder within $15 \%$ :

$\mathrm{x}(\mathrm{t})=\mathrm{x}_{1}(\mathrm{t})+\mathrm{x}_{2}(\mathrm{t})$,

where $\mathrm{x}(\mathrm{t})$ - the workplace environmental physical factors value which is investigated; $\mathrm{x}_{1}(\mathrm{t})$ - the value of the trend component of the process; $\mathrm{x}_{2}(\mathrm{t})$ - the value of the stationary component of the process.

For conditional stationary processes, the control interval was determined by its stationary part. The regression approximation was used to highlight the trend component of the process [15].

Determination of the intervals of workplace environmental physical factors values control was carried out in two stages. At the first stage, the registered data of the workplace environmental physical factors values were processed by mathematical statistics methods (was determined mathematical expectation, variance, and standard deviation) and whether the process under study was stationary or non-stationary. At the second stage (provided that the process is stationary), the period during which the process is stationary, and the intervals of workplace environmental physical factors values control were determined.

\section{Results and discussion}

\subsection{Processing registered data of the workplace environmental physical factors values using mathematical statistics methods}

At this stage mathematical expectation, variance and standard deviation should be determined. This allows you to determine a stationary process or non-stationary, as well as the stationarity period of physical factors values changes.

The mathematical expectation was determined in accordance with the equation:

$\mathrm{M}_{\mathrm{x}}=\frac{1}{\mathrm{n}} \sum_{\mathrm{i}=1}^{\mathrm{n}} \mathrm{x}_{2}(\mathrm{i})$

where $\mathrm{n}$ - sample size.

For small emission intervals of a random process $\mathrm{x}(\mathrm{t})$ (i.e. workplace environmental physical factors values changes), its level can be considered constant during such emissions:

$\mathrm{x}\left(\mathrm{t}_{0}\right)=\mathrm{x}\left(\mathrm{t}_{0}+\Delta\right)$,

where $\mathrm{t}_{0}$ - the moment when the emission begins; $\Delta$ - emissions duration.

After the corresponding mathematical transformations, the distribution function was obtained:

$\mathrm{F}(\bar{\Delta})=\mathrm{A} \int_{0}^{\bar{\Delta}} \frac{\mathrm{d} \Delta}{\Delta^{2}} \int_{0}^{\infty} \dot{\mathrm{x}}^{2} \exp \left[-\mathrm{ax} \dot{\mathrm{x}}^{2}+\mathrm{b} \dot{\mathrm{x}}\right] \mathrm{d} \dot{\mathrm{x}}$,

where $\bar{\Delta}$ - interval of workplace environmental physical factors values control;

$$
\begin{aligned}
& A=\frac{2 \exp (-C)}{\sigma^{2} R_{2} \sqrt{2 \pi \sigma^{2} \rho}} ; \\
& a=\frac{2 \Delta^{2} \rho+4 R_{2}}{\sigma^{2} \Delta^{2} \rho} ; \\
& b=\frac{2 R_{2}^{2} 1(t)}{\sigma^{2} \Delta^{2} \rho} ; \\
& c=\frac{R_{2}^{3} \gamma^{2}}{2 \rho} ; \\
& \rho=R_{4}-R_{2}^{2} ; \\
& \gamma=\frac{1(t)}{\sigma} .
\end{aligned}
$$

Mathematical expression (4) can be converted to the form:

$\mathrm{F}(\bar{\Delta})=\mathrm{A} \int_{0}^{\bar{\Delta}} \frac{1}{2 \mathrm{a}}\left\{\left[\sqrt{\frac{\pi}{4 a}} \exp \left(\frac{\mathrm{b}^{2}}{4 \mathrm{a}}\right) \operatorname{erfc}\left(-\frac{\mathrm{b}}{\sqrt{4 \mathrm{a}}}\right)\right] \cdot\left(1+\frac{\mathrm{b}^{2}}{2 \mathrm{a}}\right)+\frac{\mathrm{b}}{2 \mathrm{a}}\right\} \frac{\mathrm{d} \Delta}{\Delta^{2}}$. 
In equation (5) it was accepted $\mathrm{u}(\mathrm{h})=\frac{\mathrm{b}}{\sqrt{4 \mathrm{a}}}$,

where $\mathrm{h}$ - integration step, whose value the researcher establishes.

$\mathrm{F}(\bar{\Delta})=2 \mathrm{~A} \int_{0}^{\bar{\Delta}} \frac{\mathrm{u}^{3}}{\mathrm{~b}^{3}}\left\{\left[\sqrt{\pi} \exp \left(\mathrm{u}^{2}\right) \operatorname{erfc}(-\mathrm{u})\right] \cdot\left(1+2 \mathrm{u}^{2}\right)+2 \mathrm{u}\right\} \frac{\mathrm{d} \Delta}{\Delta^{2}}$,

or

$\mathrm{F}(\bar{\Delta})=\mathrm{A}_{1} \int_{0}^{\bar{\Delta}} \mathrm{u}^{3}\left[\sqrt{\pi}\left(1+2 \mathrm{u}^{2}\right) \exp \left(\mathrm{u}^{2}\right) \operatorname{erfc}(-\mathrm{u})+2 \mathrm{u}\right] \Delta \mathrm{d} \Delta$

where $\mathrm{A}_{1}=\frac{2 \mathrm{~A}}{(\mathrm{~b} \Delta)^{3}}$.

Having replaced the integration variable, equation (7) can be transformed to the form:

$\mathrm{F}(\bar{\Delta})=\mathrm{A}_{2} \int_{\alpha}^{\beta}\left[\sqrt{\pi}\left(1+2 \mathrm{u}^{2}\right) \exp \left(\mathrm{u}^{2}\right) \operatorname{erfc}(-\mathrm{u})+2 \mathrm{u}\right] \mathrm{du}$,

where $\quad \Delta \mathrm{d} \Delta=-\left(\frac{\gamma \mathrm{R}_{2}^{2}}{\rho}\right)^{2} \frac{\mathrm{du}}{\mathrm{u}^{3}} ; \quad \mathrm{A}_{2}=\frac{4 \mathrm{~A}}{(\mathrm{~b} \Delta)^{3}}\left(\frac{\gamma \mathrm{R}_{2}^{2}}{\rho}\right)^{2}$; $\alpha=\gamma \mathrm{R}_{2}^{2} \sqrt{\frac{2}{\rho\left(\bar{\Delta}^{2} \rho+4 \mathrm{R}_{2}\right)}} ; \beta=\gamma \sqrt{\frac{\mathrm{R}_{2}^{3}}{2 \rho}}$.

The interval of workplace environmental physical factors values control $\bar{\Delta}$ was determined provided that $\mathrm{F}(\bar{\Delta})=\delta$, where $\delta$ - confidence probability.
In this case, the mathematical expression (5) will have the form:

Understanding the function $\mathrm{x}(\mathrm{t})$ as the workplace environmental physical factors values changes for a certain period of stationarity $\mathrm{T}$, the following is true:

$x(t)=\frac{1}{T} \int_{t-T}^{T} P(\eta) d \eta$,

where $P(\eta)$ - workplace environmental physical factors value at time $\eta$.

It was accepted that $\mathrm{L}$ is the limiting value for workplace environmental physical factors for a certain class of harmfulness and danger, approved by regulatory documents. Then a graphic illustration of the change environmental physical factors over time and the period of stationarity $\mathrm{T}$ of random process $\mathrm{x}(\mathrm{t})$ the can be presented in the following form (Fig. 1) on the example of changing the dust concentration at a conditional workplace with harmful working conditions.

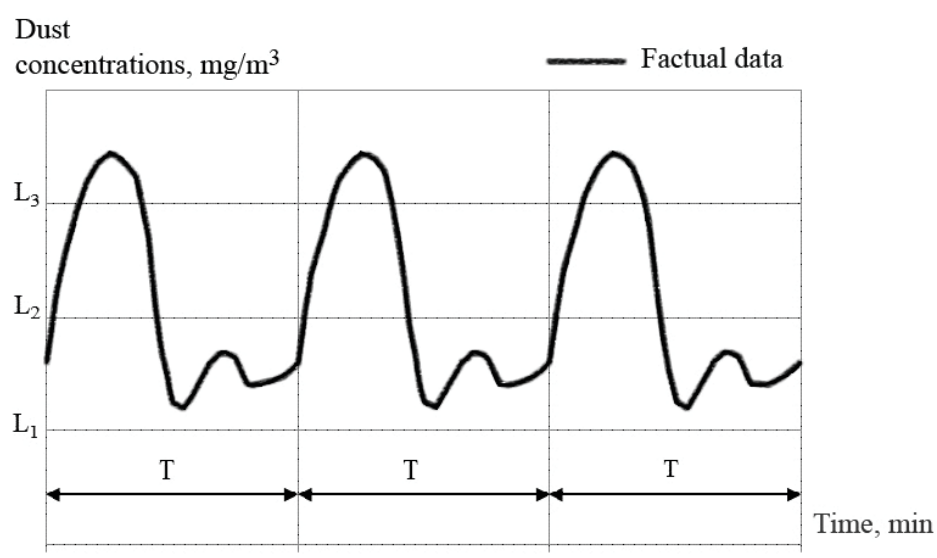

Fig. 1. Dynamics of dust concentration values (stationary process) at a conditional workplace: $\mathrm{L}_{1}, \mathrm{~L}_{2}, \mathrm{~L}_{3}-$ the limiting value (approved by regulatory documents) of the harmful substances concentration in the working zone air, defining classes of working conditions, respectively $3(1), 3(2), 3(3)^{*} ; \mathrm{T}-$ the period during which the process of dynamics of harmful substance values changes is stationary

* Assessment of working conditions was carried out in accordance with the classification of working conditions, which is valid in Ukraine [10]. However, this method can be adapted to classify working conditions according to the degree of harmfulness and danger of another state 
To calculate the intervals of control $\bar{\Delta}$ with a given accuracy, it is necessary to determine in advance the above characteristics of the random process $\mathrm{x}(\mathrm{t})$. Obviously, the $\bar{\Delta}$ value cannot exceed the $\mathrm{T}$ value, since in this case the physical factors values that exceed the $\mathrm{L}$ limiting value may not be recorded. Then the danger degree of the workplace will not be determined correctly.

\subsection{Determination algorithm of interval of harmful physical factors values control}

Determination algorithm of interval of harmful physical factors values control is clearly illustrated in Figure 2.

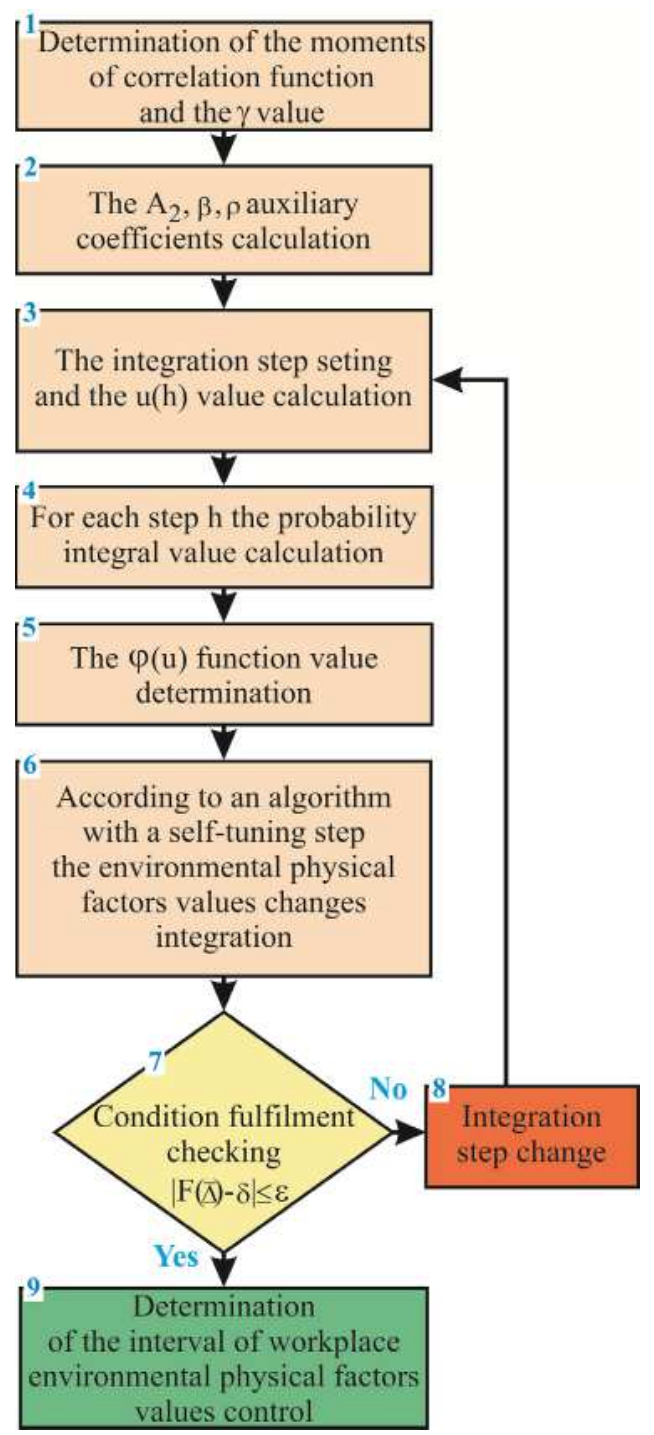

Fig. 2. Determination algorithm of the interval of workplace environmental physical factors values control
From a physical view point, the quantity calculated by the above algorithm determines the such emission duration of the random process $\mathrm{x}(\mathrm{t})$ at which the emission probability of a smaller value is equal to some small number $\delta$. In other words, if a discrete signal $\mathrm{x}(\mathrm{t})$ is received at the measuring system input with a sampling step, then such a system with probability no lower than $(1-\delta)$ will record an exceeding of the maximum permissible level. If the interval of control is chosen less than $\bar{\Delta}$, then such a system will be good to control the behaviour of the function $\mathrm{x}(\mathrm{t})$ when it approaches the maximum permissible level, but the costs for the operation and maintenance of the system will increase.

For sample size determination that is sufficient to determine the period of stationarity for a given confidence interval was proposed

$$
\begin{aligned}
& \mathrm{R}_{2}=-\frac{1}{2} \mathrm{R}^{\prime \prime}(0), \\
& \mathrm{R}_{4}=-\frac{1}{24} \mathrm{R}^{\mathrm{IV}}(0) .
\end{aligned}
$$

The $\mathrm{R}^{\prime \prime}(0)$ value can be approximately expressed in terms of a second-order difference

$$
\mathrm{R}^{\prime \prime}(0)=\frac{\mathrm{R}(\delta)-2 \mathrm{R}(0)+\mathrm{R}(-\delta)}{\delta^{2}} .
$$

Given that the function is paired, and the fact that $\mathrm{R}(0)=1$ :

$\mathrm{R}_{2}=\frac{1-\mathrm{R}(\delta)}{\delta^{2}}$.

Similarly found $\mathrm{R}^{\mathrm{IV}}(0)$

$\mathrm{R}^{\mathrm{IV}}(0)=\frac{\mathrm{R}(2 \delta)-4 \mathrm{R}(\delta)+6 \mathrm{R}(0)-4 \mathrm{R}(-\delta)+\mathrm{R}(-2 \delta)}{\delta^{4}}$,

or

$\mathrm{R}^{\mathrm{IV}}(0)=\frac{3-4 \mathrm{R}(\delta)-\mathrm{R}(2 \delta)}{\delta^{4}}$.

It is not possible to directly determine the moments of the normalized correlation function because of its breaking point at $\tau=0$. According to the results of studies, it was established [14] that the lower correlation function can be represented in the form:

$R^{\prime}(\tau)=\sigma^{2}\left(1-R_{2} \tau^{2}+R_{4} \tau^{4}\right)$,

where $\mathrm{R}_{2}=2.187 / \mathrm{T}^{2} ; \mathrm{R}_{4}=1.313 / \mathrm{T}^{4}$ 
Also according to research it was found that the normalized correlation function has the following limits:

$1-2.187\left(\frac{\tau}{\mathrm{T}}\right)^{2}+1.313\left(\frac{\tau}{\mathrm{T}}\right)^{4}<\mathrm{R}(\tau)<1, \quad \tau \in[-\mathrm{T}, \mathrm{T}]$

According to the determined values of the lower estimates $R_{2}, R_{4}$ and the results of the conducted research it is established:

$\bar{\Delta} \approx 0.3 \cdot \mathrm{T}$.

It should be borne in mind that the probability is quite small $(\delta=0.05)$ exceeding the maximum permissible level of factors. At the same time, it is advisable to take the sampling step so that it is a multiple of the period of stationarity $\mathrm{T}$ (this is convenient when organizing a cyclic control and management algorithm), that is, the largest integer is selected that satisfies the condition:

$\bar{\Delta}_{\mathrm{K}} \leq 0.3 \cdot \mathrm{T}$.

The interval of workplace environmental physical factors values control $\left(\bar{\Delta}_{K}\right)$ corresponds to the most unfavourable dynamics of changes in hazardous and harmful factors. Therefore, It can be argued that with a probability of $\mathrm{P}=0.95$, all possible excesses of the normalized values (emissions) will be recorded.

\subsection{The practical application of theoretical propositions}

The state of workplace environmental was analyzed on the basis of experimental data on physical factors values measuring of a glass and glass products manufacturing enterprise in the working area of transportation, preparation and materials mixing. The calculations were performed such values of the correlation coefficient: $\mathrm{R}=0 ; \mathrm{R}=0.5$;
$\mathrm{R}=0.75$; and confidence coefficient $\alpha=0.95$, which corresponds to the argument of the Laplace function $\varepsilon_{\alpha}=1.95$ and for value $\beta=1-\alpha=0.05$. The calculating results of the required number of measurements are presented in Table 1 .

Table 1.

The required measurements number of the physical factors values

\begin{tabular}{cc}
\hline $\begin{array}{c}\text { Correlation } \\
\text { coefficient }(\mathrm{R})\end{array}$ & Measurements number $(\mathrm{n})$ \\
\hline $\mathrm{R}=0$ & $\mathrm{n}=\frac{2 \cdot 1.95}{\ln ^{2}\left(\frac{1+0.05}{1-0.05}\right)} \approx 400$ \\
$\mathrm{R}=0.5$ & $\mathrm{n}=\frac{2 \cdot 1.95}{\ln ^{2}\left(\frac{1.5 \cdot 0.55}{0.5 \cdot 1.45}\right)} \approx 200$ \\
$\mathrm{R}=0.75$ & $\mathrm{n}=\frac{2 \cdot 1.95}{\ln ^{2}\left(\frac{1.75 \cdot 0.3}{0.25 \cdot 1.7}\right)} \approx 87$ \\
\hline
\end{tabular}

Data from 200 measurements at 1 minute interval (for each of the eight workplace environmental physical factors) were used to obtain more accurate models to take into account the correlation coefficient within $0.5 \ldots 1$. The correlation coefficient and the period of stationarity were calculated.

Table 2 shows the results of processing experimental data for actual workplace environmental physical factors values.

According to the calculations results, it is established that the correlation coefficient between the factual sample and the sample formed using the determined control interval is within $0.74 \ldots 0.88$, which satisfies the condition $\mathrm{R}>0.5$ as intended.

Table 2.

The results of processing experimental data

\begin{tabular}{llllll}
\hline \multirow{2}{*}{ No. } & $\begin{array}{l}\text { Name of environmental physical } \\
\text { factors on the workplace }\end{array}$ & $\begin{array}{l}\text { Number of } \\
\text { measurements }(\mathrm{n})\end{array}$ & $\begin{array}{l}\text { Correlation } \\
\text { coefficient }(\mathrm{R})\end{array}$ & $\begin{array}{l}\text { Period of } \\
\text { stationarity }(\mathrm{T}), \min \end{array}$ & $\begin{array}{l}\text { Interval of control } \\
(\bar{\Delta}), \min \end{array}$ \\
\hline 1 & Noise & 200 & 0.88 & 28 & 9 \\
\hline 2 & Vibration & 200 & 0.77 & 20 & 7 \\
\hline 3 & Dust & 200 & 0.76 & 9 & 3 \\
\hline 4 & Temperature & 200 & 0.78 & 80 & 27 \\
\hline 5 & Relative humidity & 200 & 0.81 & 66 & 22 \\
\hline 6 & Light & 200 & 0.74 & 70 & 24 \\
\hline 7 & Electromagnetic radiation & 200 & 0.75 & 88 & 30 \\
\hline 8 & Infrared radiation & 200 & 0.76 & 92 & 31 \\
\hline
\end{tabular}


Thus, experimental studies have shown that depending on the time the different physical factors have different duration of the stationarity period and, accordingly, necessitate a different interval for their control. Moreover, these intervals are very different from each other, which are connected with the peculiarities of technological processes of glass and products production.

\section{Conclusions}

Based on the results of theoretical and experimental studies, the following conclusions are formulated:

1. The algorithm of workplace environmental physical factors values control is proposed, which helps to identify cases when the actual values of the factors exceed the limit values (according to the current regulatory documents). The use of such an algorithm contributes to more effective monitoring of safety at the workplace.

2. A methodology has been developed for determining the interval of workplace environmental physical factors values control. It is based on the identification of patterns of change in the physical factors values. It is determined that with a constant technological process of production, the physical factors values are changed and at some time points can exceed the limit values.

3. The experimental studies have shown that depending on the time the different physical factors have different duration of the stationarity period and, accordingly, necessitate a different interval for their control. Moreover, these intervals are very different from each other, which are connected with the peculiarities of technological processes of glass and products production.

4. Was received that the interval of workplace environmental physical factors values control $\left(\bar{\Delta}_{\mathrm{K}} \leq 0.3 \cdot \mathrm{T}\right)$ corresponds to the most unfavourable dynamics of changes in hazardous and harmful factors. Therefore, It can be argued that with a probability of $\mathrm{P}=0.95$, all possible excesses of the normalized values (emissions) will be recorded.

5. The practical application of theoretical propositions showed that the correlation coefficient between the factual sample and the sample formed using the determined control interval is within $0.74 \ldots 0.88$, which satisfies the condition $\mathrm{R}>0.5$ as intended.

\section{Acknowledgements}

The authors' team is grateful to the administration of the Public Agency "National Research Institute of Industrial
Safety and Occupational Safety and Health" and National Technical University of Ukraine "Igor Sikorsky Kiev Polytechnic Institute" for the opportunity to conduct scientific research.

\section{Additional information}

The work was carried out within the scientific studies framework on the subjects of the Public Agency "National Research Institute of Industrial Safety and Occupational Safety and Health" and National Technical University of Ukraine "Igor Sikorsky Kiev Polytechnic Institute".

\section{References}

[1] S. Ragimov, V. Sobyna, S. Vambol, V. Vambol, A. Feshchenko, A. Zakora, E. Strejekurov, V. Shalomov, Physical modelling of changes in the energy impact on a worker taking into account high-temperature radiation, Journal of Achievements in Materials and Manufacturing Engineering 91/1 (2018) 27-33, DOI: 10.5604/01.3001.0012.9654.

[2] K. Hys, A. Domagała, Application of spaghetti chart for production process streamlining. Case study, Archives of Materials Science and Engineering 89/2 (2018) 64-71, DOI: 10.5604/01.3001.0011.7173.

[3] Y. Suohikova, S. Vambol, V. Vambol, N. Mozaffari, N. Mozaffari, Justification of the most rational method for the nanostructures synthesis on the semiconductors surface, Journal of Achievements in Materials and Manufacturing Engineering 92/1-2 (2019) 19-28, DOI: $10.5604 / 01.3001 .0013 .3184$.

[4] V.Ye. Kolesnik, A.V. Pavlichenko, Yu.V. Buchavy, Dynamic parameters estimation of dust emissions of heat-and-power objects of coal mines, Naukovyi Visnyk Natsionalnoho Hirnychoho Universytetu 5 (2016) 91-97.

[5] O. Tverda, K. Tkachuk, Y. Davydenko, Comparative analysis of methods to minimize dust from granite mine dumps, Eastern-European Journal of Enterprise Technologies 2/10(80) (2016) 40-46, DOI: https://doi.org/10.15587/1729-4061.2016.64840.

[6] Y. Gao, Y. Fan, J. Wang, J. Pei, Procedural management of safety regulations and rules for the chemical industry, Process Safety Progress 38/2 (2019) 1-15, DOI: 10.1002/prs.11999.

[7] S. Vambol, V. Vambol, V. Sobyna, V. Koloskov, L. Poberezhna, Investigation of the energy efficiency 
of waste utilization technology, with considering the use of low-temperature separation of the resulting gas mixtures, Energetika 64/4 (2018) 186-195, DOI: 10.6001/energetika.v64i4.3893.

[8] M. Niciejewska, Difficulties in work safety management in a company producing steel flat bars, Production Engineering Archives 17 (2017) 28-32, DOI: 10.30657/pea.2017.17.06.

[9] S. Singh Nain, R. Sai, P. Sihag, S. Vambol, V. Vambol, Use of machine learning algorithm for the better prediction of SR peculiarities of WEDM of Nimonic-90 superalloy, Archives of Materials Science and Engineering 95/1 (2019) 12-19, DOI: 10.5604/01.3001.0013.1422.

[10] Derzhavni sanitarni normy ta pravyla. Hihiyenichna klasyfikatsiya pratsi za pokaznykamy shkidlyvosti ta nebezpechnosti faktoriv vyrobnychoho seredovyshcha, vazhkosti ta napruzhenosti trudovoho protsesu: Nakaz MOZ Ukrayiny vid 08.04.2014 r № 248, Available at: https://zakon.rada.gov.ua/laws/show/z0472-14 (in Ukrainian).

[11] M. Lysyuk, Umovy pratsi na robochykh mistsyakh ta yikh atestatsiya, Dovidnyk kadrovyka 8 (2007) 94-100 (in Russian).
[12] O. Kruzhilko, V. Maystrenko, Management decisionmaking algorithm development for planning activities that reduce the production risk level, Journal of Achievements in Materials and Manufacturing Engineering 93/1-2 (2019) 41-49, DOI: https://doi.org/ 10.5604/01.3001.0013.4141.

[13] S.S. Kudryavtsev, P.V. Yemelin, N.K. Yemelina, The Development of a Risk Management System in the Field of Industrial Safety in the Republic of Kazakhstan, Safety and Health at Work 9/1 (2018) 3041, DOI: 10.1016/j.shaw.2017.06.003.

[14] K.N. Tkachuk, V.V. Kalynchyk, Vybor optymal'noho shaha dyskretyzatsyy pry kontrole élektrooborudovanyya. Pryladobuduvannya: stan i perspektyvy: materialy KHI mizhnar. nauk.-tekhnich. konf. Kyyiv, C., 2012, 262-263, Available at: https://pbf.kpi.ua/old/arch/ scientific/PB/2012/conf_PB_s8_2012.pdf (in Russian).

[15] K.N. Tkachuk, V.V. Kalinchik, Metodologiya postroyeniya sistemy monitoringa opasnykh faktorov proizvodstvennykh ob"yektov. Akademicheskaya nauka - problemy i dostizheniya: materíali III mezhdunar. nauch.-prakt. konf., North Charleston, SC, USA, CreateSpace, Vol. 1, 2014, 154-157, Available at: https://elibrary.ru/item.asp?id=21751763 (in Russian). 